\title{
CICERÓN Y AGUSTÍN. A PROPÓSITO DE LA REPÚBLICA
}

\author{
Diana Marcela Sánchez Barbosa* \\ doi:10.11144/Javeriana.uph33-67.caar
}

\begin{abstract}
RESUMEN
Para Agustín, la paz es uno de los mayores bienes tanto de la vida eterna, como de la temporal. Sin embargo, solo en la primera se presenta en forma definitiva, en la segunda es un bien dudoso e incierto. Esta afirmación cobra sentido si se tiene en cuenta que en el orden de lo creado, lo temporal, está mediado por el pecado original. Ahora bien, podría considerarse que la paz y el orden son exclusivos de la vida eterna, pero no es así, pues en la vida terrena sería imposible la existencia y el progreso de la humanidad sin la presencia de dichos elementos. De esta manera, en este escrito se intenta mostrar cómo, a pesar de que Agustín critica la figura de la república tal como la plantea Cicerón, ve en ella el elemento que posibilita y determina la paz en la tierra.

Palabras clave: San Agustín; paz; Ciudad de Dios; Cicerón; república
\end{abstract}

* Colegio Nueva Granada, Bogotá, Colombia.

Correo electrónico: diana.sanchez@javeriana.edu.co

Para citar este artículo: SÁnChez BARbosa, D.M. (2016). Cicerón y Agustín. A propósito de la república. Universitas Philosophica, 33(67), pp. 217-238. ISSN 0120-5323, ISSN en línea: 2346-2426, doi:10.11144/Javeriana.uph33-67.caar 


\title{
CICERO AND AUGUSTINE. ON THE REPUBLIC
}

\author{
Diana Marcela Sánchez Barbosa
}

\begin{abstract}
Peace is one of the biggest goods for Augustine, not only in eternal life, but also in temporal. On the one hand peace is complete in the eternal life; on the other, peace is a doubtful and uncertain good in temporal life. This statement makes sense if we consider that in the creation's order all temporal life is mediated by the original sin. In this way it could be considered that peace and order are exclusive of eternal life. Nevertheless, it is not possible, because without peace in earthly life we wouldn't be able to have progress and social life. Thus, in this paper it will be shown how Augustine, despite of his criticism on Cicero's concept of the republic, acknowledges how politics determines and makes possible peace on earth.
\end{abstract}

Key words: Saint Augustine; peace; City of God; Cicero; republic 
LOS TEMAS RELACIONADOS CON EL ÁMBITO POLÍTICO escapan al interés intelectual de Agustín. Siempre evitó involucrarse, en la práctica, en asuntos de dicha índole; sin embargo, pese a su querer, por distintas circunstancias, desde su más temprana edad se vio involucrado en la vida política de las ciudades y comunidades que habitó.

Las tareas que desarrollaba como obispo y los sucesos que acontecieron en el Imperio, sobre todo la toma de Roma por parte de Alarico y sus tropas en el año 410 , los conflictos que se vivieron al interior la Iglesia, como el cisma donatista, y finalmente, las acusaciones de los paganos contra la religión cristiana, según las cuales, esta es la principal culpable de las circunstancias por las que pasaba el Imperio, hicieron que Agustín se involucrara y asumiera decididamente tales problemáticas, siempre y ante todo, como un cristiano comprometido que se ve en la obligación de defender los intereses de la comunidad de fieles siervos de Dios.

Agustín reconoce que el hombre es un ser social por naturaleza y establece que tal condición brinda, aunque resulta problemática, ciertas ventajas, pues los grupos de hombres más o menos determinados y organizados no solo facilitan la satisfacción de necesidades primarias como el abastecimiento de alimento o el comercio, sino que llevan al hombre a buscar de forma permanente mecanismos que le permitan vivir con sus semejantes de la mejor manera posible, esto es, conservando la paz y la concordia. Más aún, indica que la amistad sincera, basada en la fe no fingida y en el amor es aquello que más consuela al hombre en la sociedad humana, llena de trabajos y calamidades, y esto no sería posible más que en un contexto comunitario.

De la misma manera que la vida de los santos, la vida del sabio y del hombre en general, es social, pues esta es la única forma en que es posible el progreso y el logro de ciertos fines (civ. Dei., 19, 5). La sociedad, es pues, una dimensión esencial tanto de la vida terrena, como de la vida celestial.

En este punto es preciso volver sobre algunos planteamientos de Agustín en torno al tema de la condición social del hombre pues, por una parte, es necesario justificar por qué dicho elemento puede considerarse una fuerza operativa en su propuesta teológica y filosófica y por otra, porque hay que esclarecer ciertas nociones fundamentales que nos llevarán a comprender cómo el cristianismo no solo supone la vida social y política, sino que la considera el eje principal de la vida del hombre. Todo ello en orden a señalar cómo la condición social y política 
de la humanidad hace parte del orden universal y contribuye a que se mantenga la paz en la vida terrena, a pesar del estado en el que se encuentra el hombre a causa del pecado.

Agustín considera que la naturaleza humana es esencialmente social y que la sociabilidad se funda en el principio de la unidad del género humano. Esto se constata en la medida en que Dios hizo que de un hombre nacieran todos los demás, y ello para que existieran en sociedad, vinculados no solo por la semejanza de la naturaleza, sino también por los lazos de parentesco. "Como quiera que cada hombre en concreto es una porción del género humano y la misma naturaleza humana es de condición sociable, se sigue de ello una gran excelencia natural: el vínculo solidario de la amistad entre todos los hombres" (b. conjug., 1, 1). Con recurrencia, Agustín vuelve sobre el tema de la sociabilidad humana y así vemos cómo, de acuerdo con Brown (2003, p. 265), es uno de los primeros cristianos que se interesa por la cuestión de las relaciones humanas y su naturaleza.

Ahora bien, Agustín identifica tres espacios en los que el hombre se desarrolla como ser social, a saber: la familia, la ciudad y el orbe de la tierra, que también denomina comunidad universal. A cada una de estas agrupaciones humanas corresponde un grado de la política. A continuación se expondrá brevemente la concepción agustiniana de familia y de orbe, dejando de lado momentáneamente a la ciudad debido a que, en orden al desarrollo del tema principal, esta merece un estudio más profundo y detallado.

\section{La familia: primera sociedad natural}

EN ROMA, LA FAMILIA ERA EN EL FONDO Y EN LA FORMA la base de la sociedad y de la República. Era una agrupación de carácter civil basada en el poder. Cada familia constituía una sociedad particular sometida a un régimen de autoridad ilimitada ejercida por el paterfamilias. Esta figura corresponde a la del padre o jefe del hogar que, por demás, es un ciudadano romano, señor de sí mismo y propietario de un cierto número de personas, ya sea por naturaleza o por derecho (Escobar, 1973, p. 12).

Agustín, conforme con la cultura latina y el derecho romano, establece que la forma más elemental y originaria de la sociedad es la familia; sin embargo, se 
distancia de la concepción estrictamente civil y jurídica, pues considera que la familia es también una organización natural que se funda en el matrimonio: la primera alianza natural de la sociedad humana nos la dan, pues, el hombre y la mujer unidos por el vínculo del matrimonio. A estos no los creó Dios por separado, uniéndolos luego como si fueran alienígenas, sino que a la hembra la creó del varón, reponiendo así la significación y la virtud unitiva en el costado, de donde la mujer fue extraída y formada (...) los hijos vienen inmediatamente a consolidar la eficacia de esta sociedad, ya que es el fruto honesto, resultante no solo de la mera unión del hombre y de la mujer, sino del comercio y trato conyugal entre los mismos. (b. conjug., 1, 1)

De la misma forma que el resto de la humanidad, la vida de la familia, en el hogar, supone una organización. La familia - el hombre, la mujer y los hijos, resultado de la unión de aquellos en matrimonio- constituye la sociedad primera. No obstante, en el hogar es posible encontrar individuos con un estatus diferente al de los mencionados, por ejemplo, los sirvientes o los esclavos. Estos son considerados parte del hogar en la medida en que por derecho le pertenecen al paterfamilias, razón por la cual tiene que cuidar de ellos también. La misión y los quehaceres propios del paterfamilias pueden compararse con los del episcopado y, por tanto, con lo que, en la práctica, Agustín vivía con la comunidad de Hipona a saber, no una vida de honra, dignidad y poder, sino un ejercicio dinámico, determinado por el cuidado de aquellos de los que se está a cargo (civ. Dei., 19, 19).

Agustín establece que el hombre es el jefe de la casa, de tal manera que la mujer, los hijos y los sirvientes deben obedecer sus designios. Esta es la única forma de mantener la vida del hogar en paz y armonía, es decir, en una "concordia bien ordenada en el mandar y obedecer de los que conviven juntos" (civ. Dei., 19, 13). La estructura de la sociedad y, en particular, las relaciones al interior de la familia se fundamentan en las reglas y en la autoridad; sin embargo, Agustín establece que la obediencia no está dada por alguna clase de temor sino, más bien, por el amor, de acuerdo con los mandatos del Creador (Harrison, 2000, p. 214).

Conforme con los mandamientos, el hombre debe procurar no solo amar a Dios y a sus semejantes, sino ayudar y velar por todos aquellos que están a su alrededor. En virtud del orden natural y de la misma vida social, la primera responsabilidad del hombre es con Dios; en segunda instancia, con aquellos a los que tiene ocasión de cuidar más propicia y fácilmente, a saber: su familia. En el hogar, los 
que se preocupan son los que mandan; y el objeto de dicha preocupación, los que obedecen: "este gobierno no es por afán de dominio, sino por la obligación de cuidar a los otros; no por orgullo de sobresalir, sino por un servicio lleno de misericordia" (civ. Dei., 19, 14).

La familia puede vivir de dos formas, la primera, según la fe, y en este caso espera los bienes eternos prometidos para el futuro; la segunda busca la paz terrena en los bienes y las ventajas de la vida temporal. Los dos tipos de familias viven en la tierra y están vinculadas unas con otras; sin embargo, se diferencian en la forma en que usan las realidades temporales necesarias para esta vida, pues mientras que aquellas que viven según la fe las utilizan para soportar y atenuar su situación presente, las otras se sirven de ellas con el fin de alcanzar la paz terrena, esto es, el orden y la armonía en el mundo, juntamente con el equilibrio entre las voluntades humanas respecto de los asuntos propios de la vida mortal.

La familia es la parte más pequeña y el principio de la ciudad, de ahí que la paz doméstica se ordene a la paz de la ciudadanía; es decir, "que la bien ordenada concordia de quienes conviven juntos en el mandar y el obedecer mira a la bien ordenada concordia de los ciudadanos en el mandar y el obedecer" (civ. Dei., 19, 16). De acuerdo con esto, el padre de familia debe tomar de las leyes de la ciudad aquellos preceptos que gobiernen su casa en armonía con la paz de aquella.

\section{El orbe de la tierra}

Agustín DENOMINA ORBE, ESTO ES, SOCIEDAD HUMANA UNIVERSAL al tercer espacio en el que el hombre se desarrolla como ser social y político. Se trata del conjunto de hombres que conforman todas las naciones y pueblos de la tierra, y que constituyen el cuerpo social universal.

De acuerdo con Gilson (1954, p. 22), podemos decir que Agustín tiene en mente una sociedad de hombres más vasta que la que puede comprender una ciudad y que, sin confundirse con el cosmos, ni tampoco igualarse a él en su extensión, agruparía a todos los hombres de la tierra. Es importante señalar que la verdadera sociedad universal, aquella a la que se refiere Agustín, tiene por fundador a Cristo y en ella solo Dios establece el orden (Markus, 1970, p. 74).

El orbe supone, entonces, a los cristianos y a las demás agrupaciones de hombres, independientemente de su raza, costumbres, creencias o ubicación 
geográfica. El Evangelio revela a los hombres la buena nueva de la salvación y, sobre todo, les enseña que son hijos de un mismo Padre; por tanto, hermanos del Hijo de Dios, que se hizo hombre para salvarlos. De esta manera, la fe en la palabra y en la persona de Cristo es el vínculo de la sociedad universal a la que no se le pueden poner límites ni de raza, ni de lugar. Es en el Evangelio y en Cristo en donde se evidencia la plenitud de la revelación, especialmente cuando establece que "no hay diferencia entre el judío y el gentil, porque el mismo Cristo es el señor de todos" (Ef. 3:6). El misterio que el Apóstol Pablo tiene que anunciar es, entonces, aquel según el cual "los gentiles recibirán la misma herencia que los judíos, pues son miembros del mismo cuerpo y tienen parte en la misma promesa que Dios hizo en Jesucristo" (Gilson, 1954, p. 29).

La sociedad universal que plantea Agustín es aquella en la que desaparecen todas las barreras y en donde quedan abolidas todas las distinciones que impiden de alguna manera que se dé la unión universal de los seres humanos en un solo cuerpo cuya alma es la fe. Sin embargo, es claro que en el orbe no solo hay más hombres sino mayor diversidad entre ellos; por eso, la situación allí resulta más problemática que en la familia o en la ciudad, puesto que no es tan clara la relación de parentesco, no hay una relación fraterna ni de cuidado mutuo, como en el caso de la familia, y frente al caso de la ciudad, el orbe supone una dimensión pública y política más compleja.

El tema de la sociedad, fragmentada y con problemas de comunicación, es objeto del interés de Agustín, pues sabe que el pueblo de Dios hace parte de ella, y aunque peregrina por este mundo mientras esté en él, su comunidad convive con no cristianos y necesita de ellos en la vida cotidiana; además, participa de las estructuras sociales, civiles y políticas de la República, y de la dinámica del orbe en general. Ante esta perspectiva, Agustín intenta dar respuesta a la pregunta de cómo es posible que el hombre, a pesar de la situación en la que vive, encuentre una opción que le permita permanecer en paz. La situación de la sociedad del norte de África que se divide a causa del cisma de la Iglesia es una oportunidad para señalar la complejidad de la vida en sociedad.

La comunidad cristiana africana consideraba que la Iglesia suponía un estado de separación respecto del mundo; aquella se hallaba en una esfera de pureza y santidad, mientras que este estaba inmerso en el pecado y la oscuridad. De esta manera, la Iglesia se convertía en la sociedad de los santos y su santidad se hallaba 
en su interior. La Iglesia y el mundo se excluían y no podían coincidir en nada. Para los africanos, la Iglesia era una comunidad distinta del mundo y se constituía como una alternativa a este.

Es a propósito de este tema que Agustín se involucra en una de las situaciones más complejas de su época: el cisma de la Iglesia a causa de la disputa con los donatistas. Lo que está en juego es no solo la unidad de la Iglesia, sino su postura frente al mundo y la relación con sus miembros ${ }^{1}$.

En el año 388, luego de su paso por Roma y Milán, Agustín regresa a África con una nueva perspectiva de la vida. La situación y la disputa que se presentaba entre católicos y donatistas, aunque no le resultaba desconocida, le era ajena. La asimiló rápidamente, pero desde un punto de partida distinto, "con un adiestramiento sumamente personal como filósofo, y con una posición que había evolucionado en el curso de su adaptación al episcopado" (Brown, 2003, p. 228). Las circunstancias no solo suponían hacer frente a un problema teológico sino intervenir directamente en la vida civil, pues la situación de violencia y confusión había cruzado los límites de los templos y el espacio local, para llegar a las cortes imperiales y a otras instancias.

Ahora bien, contrario a la postura donatista, Agustín vio en la Iglesia el elemento que lejos de ser una alternativa distinta de la sociedad civil, se hace compatible con ella, y en esta conjunción puede asimilar, transformar y perfeccionar

1 El origen del cisma donatista se remontaba a la época de las últimas persecuciones bajo Diocleciano. En el norte de África hubo entonces algunos obispos que, intimidados por las armas, accedieron a entregar las Sagradas Escrituras a las autoridades. Hubo otros que, por el contrario, resistieron con heroísmo ante las amenazas, llegando incluso a entregar su vida antes que las Escrituras. Pasada la persecución, y ya bajo el reinado de Constantino, los dos bandos no pudieron ponerse de acuerdo en la elección de sus obispos. En efecto, quienes permanecieron fieles en la prueba rechazaron la validez del nombramiento de aquellos que habían flaqueado, pues la apostasía en que habían incurrido quienes entregaron los libros sagrados no solo los hacía indignos de recibir cualquier sacramento, sino que los había excluido de la propia Iglesia. Quienes habían cedido aducían, por su parte, que la eficacia del sacramento no depende de la santidad del ministro, y no estaban dispuestos a renunciar a su carácter universal, esto es, católico (...) A lo largo de los últimos decenios la situación había llegado a ser muy complicada, pues aparte de los desacuerdos teológicos otros temas enrarecían las relaciones. Estaba, en primer lugar, el acceso a subvenciones del Estado y exenciones fiscales, que cobijaban a los católicos, pero no a los donatistas (...) No menos problemático era el hecho de que en todo ese tiempo la sociedad africana se había ido polarizando alrededor de las dos Iglesias, hasta el punto de que los católicos tendían a ser identificados con el segmento romano, urbano y próspero de la población, mientras los donatistas se habían hecho fuertes en el medio autóctono (Flórez, 2004, p. 108). 
los lazos de las relaciones humanas. En este sentido, Agustín estima que, a pesar de que la humanidad se encuentre sumida en una situación de discordia y de conflicto permanente, la Iglesia católica es la única institución que llena de confianza, extendida por todo el orbe, establecida con el respeto de los emperadores cristianos, buscada por nobles e intelectuales es capaz de guiar las masas del mundo civilizado. Refiriéndose a la Iglesia, Agustín establece lo siguiente:

Eres tú quien somete las esposas a los maridos (...) mediante la obediencia fiel y casta; colocas a los maridos por encima de sus esposas; unes a los hijos con sus padres mediante una esclavitud libremente aceptada, y colocas a los padres por encima de sus hijos en piadosa dominación. Unes hermano con hermano mediante los lazos de la religión, aún más firmes y tirantes que los de la sangre. Enseñas a los esclavos a ser más leales con sus amos (...) y a los amos (...) a inclinarse más a convencerlos que a castigarlos. Juntas a ciudadano con ciudadano y a nación con nación; y juntas sin duda, a todos los hombres en recuerdo de sus primeros padres, y no solo mediante los vínculos sociales, sino con cierto sentimiento de parentesco común. Tú enseñas a los reyes a gobernar en beneficio de su pueblo, y eres tú quien advierte a los pueblos que sean más obedientes a sus reyes (mor., 1, 30, 63).

La cuestión común entre Agustín y los donatistas es, en el fondo, la forma de comprender la Iglesia. Los donatistas defendían la idea de que solo ellos habían mantenido totalmente la ley cristiana, de ahí que negaran, por ejemplo, la validez del bautismo cuando no era administrado por algún miembro de la verdadera Iglesia, con lo que la convertía en una institución cerrada a la comunidad procedente del exterior. La Iglesia de los donatistas es causa de indignación para Agustín, pues era limitada, ponía en entredicho la palabra de Dios al negar su universalidad y su santidad y porque introducía al pueblo cristiano en una suerte de comunidad estratificada.

Para Agustín, por el contrario, la Iglesia es un lugar abierto a todo el mundo, no solo a los cristianos, por eso advierte que allí es posible encontrar borrachos, miserables, embusteros, adúlteros y toda clase de hombres, que de la misma manera que están allí, llenan los teatros en las fiestas paganas. La Iglesia es un cuerpo mixto y en su interior, evidentemente, era posible encontrar pecadores; también es una dinámica compuesta por elementos móviles que le dan el carácter 
universal y, lejos de la anticuada, estancada y limitada Iglesia de Cipriano, la de Agustín está en permanente renovación y expansión.

La Iglesia existe no para desafiar a la sociedad, sino para conducirla y esto con base en la justicia verdadera que depende del orden del amor establecido por Dios. Caso contrario el de Cicerón que considera que el gobierno dependerá de las condiciones y las características de la comunidad en cuestión, por lo que será el derecho, esto es, un cuerpo jurídico común aceptado por las personas que conforman la colectividad, lo que determine el orden y procure la concordia entre los ciudadanos. Será esta idea la que Agustín retomará para mostrar por qué Roma no puede considerarse una auténtica república.

3. La República

\subsection{CICERÓN: LA REPÚBLICA}

LUEGO DE ESTABLECER QUE LA POLÍTICA ES una de las actividades propias del sabio, siendo además superior a la estrictamente teórica, Cicerón reflexiona en su obra Sobre la república a propósito de cuál puede ser la mejor forma de gobierno. Sin embargo, el estudio de dicho tema carece de sentido si no se indica cuál y de qué tipo es la colectividad que se espera dirigir. Por esta razón, antes de pasar a examinar cada una de las formas de gobierno -monarquía, aristocracia, democracia, y sus degeneraciones: tiranía, oligarquía y anarquía-, determina qué es la república², pues "nunca podrá entenderse aquello de lo que se va a hablar si no se entiende antes lo que es" (Rep. I, 24, 38).

Cicerón define la república como "cosa que pertenece al pueblo" (Rep. I, 25, 39), y precisa que pueblo no es todo conjunto de hombres reunido de cualquier manera, sino el conjunto de una multitud asociada por un mismo derecho que sirve a todos por igual. Señala que la sociedad es natural al hombre en la medida

2 Es importante señalar que Cicerón piensa concretamente en la República romana, con sus características, su legislación y su contexto particular. Al final del libro I del De republica Escipión precisa esta idea: "Digo, pues, solemnemente, así lo pienso y afirmo, que de todas las repúblicas, no hay ninguna que, por su constitución, por su estructura o por su régimen, sea comparable con aquella que nuestros padres recibieron de los antepasados y nos trasmitieron a nosotros" (Rep. I, $46,70)$. 
en que es esencial para el logro de una vida feliz y virtuosa. Además, la sociedad surge no por debilidad y necesidad de protección, sino por una cierta tendencia asociativa natural de los hombres que apunta a una aceptación consensuada de las leyes y a la persecución del interés común.

Hay que hacer algunas precisiones a propósito de esta definición. Lo primero que hay que advertir es que en la obra del orador no hay nada que explique qué entiende por cosa. Sin embargo, podemos señalar que en el contexto de la cultura latina cosa puede ser entendida, por un lado, como un objeto, por otro, como un cierto ejercicio.

En cuanto al pueblo, Cicerón establece que no es una simple agrupación humana, sino una sociedad basada en el consentimiento del derecho y en la comunidad de intereses. Un pueblo es "un conjunto de personas que se ha dado unas normas en función de un interés común articulado en ese acuerdo normativo o jurídico que es el contenido directo y concreto de la abstracta res" (Mas, 2006, p. 196). Esta forma de comprender lo que es el pueblo supone dos elementos: primero, la unión de unos hombres; segundo, un derecho o normatividad común del que pueden servirse todos aquellos que pertenecen a la comunidad. El derecho común es lo que hace que un agregado humano se convierta en un pueblo y que, por tanto, sea posible hablar de gobierno público o república: "así, pues, todo pueblo, que es tal conjunción de multitud, como he dicho, toda ciudad, que es el establecimiento de un pueblo, toda república, que, como he dicho, es lo que pertenece al pueblo, debe regirse, para poder perdurar, por un gobierno" (Rep. I, 26, 41).

Para Cicerón un agregado humano espontáneo no puede considerarse un pueblo, pues este se caracteriza por poseer un orden común entre los distintos hombres que lo constituyen, a saber, los mejores, los que actualmente lo gobiernan y el común de los ciudadanos. Este orden está dado por el derecho común que ha sido establecido para todos y del que todos pueden servirse, de ahí su doble carácter de iuris consensus y de communio utilitatis. Lo primero se refiere al derecho como común a todo el pueblo, aunque no es creado por algún tipo de consenso o acuerdo entre los ciudadanos; lo segundo concierne a su disponibilidad, es decir, al hecho de que el pueblo pueda servirse de él. Un pueblo será tal, entonces, cuando las personas que lo constituyen acepten un cuerpo jurídico común que rija su vida y su conducta. El derecho, el deber y el poder serán así los elementos que, para Cicerón, determinarán la armonía y la concordia y, con ello, la 
constitución de un pueblo. $\mathrm{Al}$ respecto dice Cicerón: "recordad lo que he dicho al principio: que la república no puede conservar su estabilidad a no ser que se de en ella un equilibrio de derecho, deber y poder, de suerte que los magistrados tengan la suficiente potestad, el consejo de los hombres principales tenga la suficiente autoridad y el pueblo tenga la suficiente libertad" (Rep. II, 33, 57).

La república no es el conjunto de los bienes de los que se encarga la clase política, tampoco las instituciones. Es algo más abstracto. Se trata del consenso jurídico que Roma se ha dado a sí misma y en cuya raíz, de acuerdo con Cicerón, se encuentra la misma naturaleza ordenando hacer lo bueno y prohibiendo lo malo.

Cicerón considera que la fuente de la ley y del derecho ha de buscarse en una "filosofía esencial que, lejos de intereses privados y egoístas, enseña que hay una razón cósmica que se manifiesta como ley en tanto que razón fundamental, ínsita en la naturaleza, que ordena lo que hay que hacer y prohíbe lo contrario" (Leg. I, 18). A propósito de esta afirmación hay que decir, con Salvador Mas (2006), que de la misma manera que existen dos ámbitos jurídicos, a saber, el propio y el común, hay también dos sentidos de ley que Cicerón advierte, "el estrictamente romano, de acuerdo con el cual la ley sanciona por escrito órdenes y prohibiciones, y un sentido universal que el Arpinate, alejándose del contexto más romano, elabora tomando pie en la filosofía griega: no la ley positiva, sino la summa lex principio constitutivo del derecho y que nació para todos los siglos, antes de que se escribiera ninguna ley o de que se organizara ninguna ciudad" (Mas, 2006, p. 181).

La ley y el derecho son, entonces, el eje de la vida de la república; de hecho, Cicerón afirma de manera contundente que la república es sus leyes 33 . Sin embargo, hay que tener en cuenta que tanto el derecho de la ciudad (ius civitatis) como el de la comunidad de hombres (ius humanum) están subordinados al ius naturale "que atañe a todos los humanos y a todas las cosas en tanto que partes de un orden querido por los dioses providentes o establecido por la razón universal” (Mas, 2006, p. 186).

3 "Porque ellas son el vínculo de dignidad de que gozamos en la República, ellas el fundamento de la libertad, ellas la fuente de la justicia, el alma, el espíritu, la sabiduría y el pensamiento de la ciudad radican en las leyes. Lo mismo que nuestros cuerpos sin inteligencia, así la ciudad sin ley no puede servirse de sus elementos, que son como sus nervios, su sangre y sus miembros" (Pro Cluent. 53, 146). Ver: Mas, 2006, p. 190. 
Volviendo al diálogo, Escipión se vale de la analogía de la armonía musical ${ }^{4}$ para explicar cómo la república, a pesar de la diversidad que hay en ella, vive y se conserva gracias a la concordia entre sus habitantes. La concordia, esto es, un cierto sentimiento de armonía y amistad entre los ciudadanos, es, sin embargo, resultado de la justicia, y en ningún caso aquella puede existir sin esta. En consecuencia, Cicerón establece que no es posible gobernar una república sin el recurso a la justicia perfecta (Rep. II, 44, 70). Esta es la más espléndida de todas las virtudes, consiste en "no causar daño a nadie, si no es injustamente provocado, y usar los bienes comunes como comunes y los privados como propios" (De Off. I, 20).

Si se retoma la definición propuesta antes hay que decir, entonces, que sin justicia no es posible un pueblo, y en la medida en que este es fundamento de la ciudad y así, de la República, no es posible que exista una República sin que impere en ella la justicia.

Finalmente, Cicerón señala que la república es un bien útil al pueblo en la medida en que se gobierne bien. De esta manera, los que hayan de gobernar, para hacerlo eficientemente, deben, primero, defender los intereses de los ciudadanos de forma que cuanto hagan lo ordenen a ellos olvidándose del propio provecho; segundo, han de velar sobre toda la república, ya que atendiendo a la protección o el bienestar de una parte, puede descuidarse el resto (De Off. I, 25, 85), caso en el que la res ya no será pública, sino de una parte.

Por tanto, en la república todo debe estar dispuesto en favor de la vida feliz y honrada de la comunidad. Al ser esto la causa principal del pueblo, la república debe velar por que dicho fin se alcance, ya sea por medio de las leyes, ya sea por medio de sus instituciones, ya sea por medio de la educación de sus ciudadanos.

4 "Porque del mismo modo que en los instrumentos de cuerda o de viento, o en el mismo canto de varias voces, debe guardarse un concierto que da por su mismo ajuste unidad y congruencia a muy distintas voces, que los oídos educados no toleran que se altere o desentone, y ese concierto, sin embargo, se hace concorde y congruente por el gobierno de voces muy distintas, así también, una ciudad bien gobernada es congruente por la unidad de muy distintas personas, por la concordia de las clases altas, bajas y medias, como los sonidos. Y la que los músicos llaman armonía en el canto, es lo que en la ciudad se llama concordia, vínculo de bienestar seguro y óptimo para toda república, pues ésta no puede subsistir sin la justicia” (Rep. II, 42, 69). 


\subsection{Agustín: LA REPÚBLICA}

A propósito del tema de la RePública, Agustín no asume una perspectiva ni como filósofo indiferente al cristianismo, ni como cristiano indiferente a la filosofía; más bien, hace frente al tema como un cristiano que juzga la filosofía, asume sus conceptos y los reforma a la luz de la fe.

Lo que le interesa a Agustín no es investigar qué es una república, desde el punto de vista material, es decir, en cuanto espacio físico, sino en sentido social, lo cual solo es posible apelando al modelo por excelencia: Roma. La investigación comienza con la pregunta por el momento en que Roma mereció el nombre de república. Para responder a ello es necesario establecer qué es una república. Agustín vuelve, entonces, sobre la definición pagana más aceptada, esto es, la de Cicerón y, a partir de ella, construye y expone la propia.

Para Agustín es claro que todos los hombres desean ser felices y esto lo ansían con amor apasionado. En la felicidad ponen el fin de sus apetencias y nadie puede amar lo que en su esencia o en su cualidad ignora; es decir, no es posible desconocer la esencia de lo que se ama, de ahí que todos los hombres conozcan la vida feliz. Todos los bienaventurados poseen lo que quieren, aunque no todos los que poseen lo que quieren son felices; al contrario, son miserables todos los que no tienen lo que desean o poseen lo que no quieren rectamente. Solo es feliz el que posee todo lo que desea y no desea nada malo (Trin., 13, 6, 9).

El sumo bien es la vida eterna y el sumo mal la muerte eterna y "para conseguir una y librarse de la otra es necesario vivir bien” (civ.Dei., 19, 4). Lo que Agustín denomina vivir bien no es producción nuestra, ni es algo que podamos lograr en esta vida. Se presenta a causa de nuestra fe y de la búsqueda que emprendemos por nuestra creencia y esperanza. Agustín indica, además, que la felicidad es independiente de las eventualidades propias de la fortuna y de los bienes externos, de ahí que para los cristianos el bien supremo sea la paz eterna y perfecta, aquella en la que los hombres no experimentan ningún tipo de adversidad.

Para el cristiano, la felicidad absoluta no puede ser lograda en la vida temporal y terrena, ya que la condición pecadora del hombre le impide vivir plenamente feliz, por lo que solo puede ser bienaventurado en esperanza. El cristiano aún no es feliz, pero espera conseguir con paciencia la felicidad que aunque no posea le ha sido prometida. La verdadera bienaventuranza es aquella que supone la 
sabiduría, pero no la que persiguen los filósofos, sino la que se identifica con Cristo y con la Trinidad, que está mediada por la fe, la esperanza y el amor, y debido a que se obtendrá cuando el hombre oriente su amor al Creador, solo se logrará plenamente en la vida eterna de la paz.

Agustín establece que la vida eterna de la paz es lo único que puede ser considerado absoluta bienaventuranza y solo es posible en la Ciudad de Dios; sin embargo, indica que "es tan singular el bien de la paz, que aun en las cosas terrenas y mortales no solemos oír cosa de mayor gusto, ni desear objeto más agradable, ni, finalmente, podemos hallar cosa mejor" (civ.Dei., 19, 11). En las cosas humanas y en la naturaleza común no hay nada, ni nadie que no guste y disfrute de tener paz; ejemplo de ello es que aquellos que desean la guerra, desean vencer y así alcanzar la paz o aquellos que con malicia y codicia turban la tranquilidad de otros, desean que en su hogar, con su mujer y sus hijos exista siempre paz. Más aún, de no existir algún tipo de paz en la vida terrena sería imposible la existencia y el progreso de la humanidad.

En este contexto, Agustín retoma la definición ciceroniana de república ${ }^{5}$, atendiendo a su promesa ${ }^{6}$ de examinarla cuidadosamente. Demostrará que de acuerdo

5 "Porque brevemente define-Cicerón-la república, diciendo que es cosa del pueblo, cuya definición, si es verdadera, nunca hubo república romana, porque nunca hubo cosa del pueblo, cual quiere que sea la definición de república. Pues definió al pueblo diciendo que era una junta compuesta de muchos; unida con el consentimiento del derecho y la participación de la utilidad común. Y más adelante declara qué significa lo que llama consentimiento del derecho; manifestando con esto que sin justicia no se puede administrar ni gobernar rectamente la república” (civ. Dei., 19, 21).

6 "Examinen atentamente los que tanto ensalzan, qué tal fue aun en la época en que florecieron aquellos antiguos varones y celebradas costumbres, si acaso floreció en ella -Roma- la verdadera justicia, o si quizá entonces tampoco vivía por el rigor de las costumbres sino que estaba pintada con bellos colores, la cual aún el mismo Cicerón, ignorándolo cuando la celebraba y prefería, lo expresó, pero en otro lugar hablaremos de esto, si Dios lo quiere, procurando manifestar a su tiempo, conforme con las definiciones del mismo Cicerón, cuán brevemente explicó lo que era república y lo que era pueblo en persona de Escipión, conformándose con él otros muchos otros pareceres, ya fuesen suyos o de los que introducen en la misma disputa, donde sostiene que aquella nunca fue república, porque jamás hubo en ella verdadera justicia, pero según las definiciones más probables en su clase, fue antiguamente República, y mejor la gobernaron y administraron los antiguos romanos que los que siguieron después; en atención a que no hay verdadera justicia, sino en aquella República cuyo Fundador, Legislador y Gobernador es Cristo, si acaso nos agrada el llamarla República, pues no podemos negar que ella es un bien útil al pueblo; pero si este nombre, que en otros lugares se toma en diferente acepción, estuviese acaso algo distante del uso de nuestro modo de hablar, por lo menos la verdadera justicia se halló en aquella Ciudad de quien dice la Sagrada Escritura: Cuán gloriosas cosas están dichas de la Ciudad de Dios" (civ. Dei., 2, 21). 
con la formulación del Arpinate, en Roma nunca existió verdadera justicia, por esto, tampoco una congregación de hombres asociada por un derecho común, pues sin justicia no es posible la existencia del derecho, ni, por consiguiente, un pueblo.

Ahora bien, es claro que la lectura que hace Agustín de la definición ciceroniana se centra en la noción de justicia, por ello, el énfasis está puesto en mostrar que esta nunca existió en la república romana tal como la entendió el orador. El interés de Agustín, sin embargo, va más allá de esto y la exposición sirve a otros objetivos (O’Daly, 2004, p. 207).

El primero de dichos objetivos es entrever cuáles serían las implicaciones de la justicia al servicio de Dios, esto es, la distinción entre lo que constituye la justicia para los cristianos y la realidad de la república romana cuando se rinde al culto de los falsos dioses (civ. Dei., 19, 21.). En segundo lugar, está proponer una definición alterna, que considere el elemento cristiano y que justifique por qué solo puede denominarse verdadera república a la Ciudad de Dios. En tercer lugar, Agustín, de acuerdo con el plan de la obra, hace frente a las acusaciones paganas según las cuales el cristianismo prepara la ruina de la república, puesto que enseña al hombre a renunciar al mundo y, por tanto, aparta al ciudadano del servicio al Imperio. Finalmente, Agustín se sirve de la definición de Cicerón para mostrar que, pese a la situación trastornada de la humanidad, esta goza de cierta paz y tranquilidad, y ello gracias a las dinámicas públicas y políticas que son propias de las naciones.

Para Agustín, de acuerdo con la definición de Cicerón, en Roma nunca existió un pueblo y, por lo tanto, tampoco una república. Esto lo ratifica el hecho de que el pueblo es definido como una multitud asociada por un mismo derecho que sirve a todos por igual. Por ello, en la medida en que en Roma no existió verdadera justicia, tampoco un derecho que se fundamente en ella, y dado que sin este no hay nada que asocie a la multitud, los romanos no pueden llamarse pueblo, ni Roma una república.

Como se señaló anteriormente, para Cicerón la justicia es condición fundamental para la existencia de la concordia entre los hombres y, así, de la república. Aunque Agustín ratifica esta idea, no por ello acepta que Roma haya sido, efectivamente, una república. Solo la la Ciudad de Dios merece tal título, en la medida en que solo en ella existe verdadera y perfecta justicia. Sin embargo, "debe existir por lo menos una segunda república, aquella que constituyen todos los hombres 
cuya cabeza no es Cristo; pero ésta no es casi más que el desecho de la primera y solo existe a causa de ella. No existiría república de la injusticia, si no existiera una de la justicia. Toda sociedad digna de ese nombre es, pues, o la Ciudad de Dios, o la definida con relación a ella" (Gilson, 1954, p. 51).

Si bien Agustín establece claramente qué entiende por justicia, concretamente por verdadera justicia, no hace lo mismo con lo que podría ser una falsa justicia. Es importante señalar inicialmente que, para Agustín, la justicia en sentido pleno es la divina. Esta se revela a los hombres en la misericordia de Dios y en su voluntad de que la humanidad se salve por la redención de Cristo que reconcilia a los hombres con el Creador. Los hombres participan de la justicia divina; en ellos hay por lo menos un recuerdo de lo que es la justicia, pues fueron creados a imagen y semejanza de Dios, y a pesar de su condición caída la naturaleza humana no se deformó totalmente.

Ahora bien, respecto de la verdadera justicia se puede decir que Agustín retoma la idea clásica de justicia distributiva, que consiste en dar a cada cual lo que le es debido, pero la transforma en términos cristianos señalando que la justicia es dar a Dios y al prójimo el amor que se les debe en virtud del doble mandamiento del amor. La justicia verdadera consiste entonces, en una recta relación cuyo fundamento es un amor ordenado a la jerarquía de bienes establecidos por Dios como objetos de amor y deseo.

Antes de la caída los primeros hombres gozaban de la paz y la bienaventuranza absolutas, y su total obediencia a Dios les garantizaba una recta y justa relación con Él. A causa del pecado quedaron privados de tal condición y la relación de justicia se deformó, pues los hombres dejaron de orientar su amor hacia Dios. En este sentido es posible afirmar que la falsa justicia es imperfecta porque es producto del pecado; en el mejor de los casos se trata de una justicia parcial, contingente y sujeta al cambio debido a que se sustenta en la experiencia. De este modo hay que afirmar que en Roma no existió justicia, pues si esta se comprende en el sentido distributivo antes expuesto, “¿qué justicia, pues, será la del hombre que al mismo hombre le quita a Dios verdadero y lo sujeta a impuros demonios?, ¿es esto dar a cada uno lo que es suyo?" (civ. Dei., 19, 21).

Si la meta humana es el disfrute de Dios, esto es, adherirse con amor a Él por sí mismo, todo lo que hace y lo rodea debe estar ordenado a alcanzar dicha meta. Por ello, Agustín establece que todo lo que no es Dios debe ser utilizado de tal 
forma que conduzca a Él, pues "utilizar se refiere al uso de lo que es conducente a obtener lo que amas, con tal de que sea digno de ser amado" (doc. Chr., 1, 22, 20). En este orden de ideas, es preciso decir que para Agustín la virtud es el medio por el que la moral se ordena y dirige a una meta apropiada; mientras que para Cicerón, por el contrario, es no solo el fundamento de la república, sino la meta y la finalidad de la vida humana. Por esta razón, para Agustín, el Imperio Romano creció porque muchos de los hombres que lo construyeron y lo habitaron guardaban cierta integridad en su clase, la suficiente para construirlo, acrecentarlo y conservarlo; con lo que se evidencia que las virtudes civiles tienen un gran valor, de lo que es testimonio aquel gran Imperio. Siguiendo a Markus (1970, p. 74), se señalamos que Agustín reconocerá la necesidad del Estado y de la ley natural para iluminar la vida del hombre que, por su condición pecadora no puede, por sí mismo, comprender y seguir los caminos del orden del universo.

Hasta este momento es claro queAgustín sigue a Cicerón en torno al tema de la necesidad y la utilidad de la virtud para la vida social y política; no obstante, se aleja de él puesto que considera que la virtud civil no es suficiente para garantizar la vida de la república, ya que para esto es necesario que se una a la verdadera religión. Pero, ¿cómo es posible que el ejercicio de la virtud civil haya sido suficiente para el progreso del Imperio y que luego necesite de la verdadera religión para que resulte eficaz y conveniente a la vida del hombre? Agustín establece que lo que es apto en un tiempo, no lo es necesariamente en otro, por lo que en este caso la virtud se juzga no por ella misma, sino por el objeto de que depende ${ }^{7}$.

Entonces, para Agustín, el problema del Imperio y los males que le ocurrieron no son resultado del establecimiento de esta o aquella doctrina, de las

7 "Fue apto para los antiguos tiempos un sacrificio que Dios preceptuó, pero ahora no lo es. Porque ahora ha preceptuado algo que es apto para este tiempo, pues Él sabe mejor que ningún hombre lo que se ha de utilizar convenientemente en cada tiempo. Cuando lo utiliza, añade, disminuye, quita, pone, es Creador inmutable de las cosas mudables, y es también su gobernador. Así va transcurriendo la hermosura de las edades del mundo, cuyas partículas son aptas cada una a su tiempo, como un gran cántico de un inefable artista, para que los que adoran dignamente a Dios pasen a la contemplación eterna de la hermosura, aun mientras dura el tiempo de la fe. (...) Dios no manda nada de esto por su propio interés, sino por interés del que obedece. Por eso es verdadero Señor, porque no necesita de su siervo y, en cambio, su siervo necesita de Él (...) Se trata de símbolos de las realidades que Él reparte, ya infundiendo virtudes en el alma, ya para conseguir la salvación eterna. La celebración y ejecución de esas acciones simbólicas son obligaciones de piedad para utilidad nuestra y no de Dios" (Ep. 138, 1, 5). 
decisiones o medidas tomadas por estos o aquellos emperadores, sino que su decadencia se debió a la avaricia de sus costumbres corrompidas, al hecho de que una perversidad cruel se apoderó de las conciencias de sus habitantes, a la aceptación de la impunidad de los vicios y a la fe en falsos dioses. Mostró Dios en el opulento y célebre Imperio Romano cuánto valen las virtudes civiles, aun sin la verdadera religión (Ep. 138, 3: 17); sin embargo, mostró también que la prosperidad de la república solo puede darse si esta se fundamenta en una sociedad de piedad y justicia. No se trata de ofrecer la otra mejilla a aquel que nos ha dado una bofetada, ni de dar el manto a aquel que por medios violentos quiere quitarnos la túnica; se trata, más bien, de subyugar el mal que hay en el hombre por medio del bien, para que el hombre se libre del mal. En palabras de Agustín:

no [se trata] del mal exterior y ajeno, sino del mal propio e íntimo, por el que es arruinado más grave y perniciosamente que por la crueldad de cualquier enemigo exterior. Luego quien vence al mal con el bien o pierde con paciencia las comodidades temporales, muestra cuán despreciables son comparadas con la fe y la justicia; precisamente por amarlas demasiado era malo. De ese modo, el que injuria aprende del injuriado la futilidad de esos intereses por los que hizo la injuria, se arrepiente y vuelve a la concordia, interés supremo de la ciudad; no vuelve derrotado por enemigos crueles, sino por la benevolencia del que toleró la injuria. (Ep. 138, 2, 11)

Agustín no desconoce ni la necesidad, ni el alcance de las virtudes, tampoco de las instituciones civiles, pero señala que ambas resultan imperfectas si no están en función de la verdadera religión, pues esta es la única manera de alcanzar la perfección de los ciudadanos y la eternidad de la república. El cristiano no debe despreciar nada de cuanto verdadero y útil ha encontrado el hombre, porque la verdad, de cualquier parte que venga, proviene de Dios. Agustín sabe que toda comunidad humana, cristiana o no, se sirve de los bienes propios del mundo, pues ellos hacen que la vida se soporte más fácilmente. El uso de las cosas del mundo es común a fieles e infieles, no obstante, el uso y la finalidad que se les da es distinto. Los bienes del alma, del cuerpo y del mundo no deben ser despreciados, todo lo contrario, deben ser aprovechados en beneficio del hombre, pero ello solo se logrará cuando se busquen y se usen con miras a Dios.

De acuerdo con Cicerón, Agustín establece que una multitud de hombres unidos entre sí por algún vínculo social no es un pueblo, por lo que dista del 
Arpinate en la medida en que el fundamento del pueblo no es la ley o el derecho, sino el amor común de bienes realmente idénticos. Agustín replantea la definición y establece que un pueblo "es una congregación de muchas personas, unidas entre sí por la comunión y conformidad de los objetos que ama” (civ. Dei., 19, 24). De esta manera, un pueblo es realmente tal cuando en él existe la concordia de las razones y de los corazones que liga el conjunto de los individuos y de las personas. Un pueblo se constituye cuando su vínculo es la concordia. Conforme con esta nueva definición es posible tanto reconocer pueblos dignos de tal nombre, aunque en ellos no impere la justicia, como conceder, por tanto, que "el pueblo romano es un pueblo, y su asunto principal sin duda alguna es la república" (civ. Dei., 19, 24). Para Agustín la república, en este sentido, es el interés del pueblo que es "una muchedumbre reunida por el vínculo de la concordia" (ep. 138, 2, 10). Entonces, no es posible negar a Roma el nombre de pueblo, pues a pesar de su decadencia política y al deterioro de sus costumbres, en ella subsistió "una congregación de seres racionales, unidos en la comunión unánime de todos sus miembros en las cosas que aman" (Gilson, 1954, p. 57).

Agustín le da un giro a la definición de pueblo que propone Cicerón y la lleva del ámbito de lo jurídico a lo que podríamos denominar comunitario o vital. El énfasis ya no está puesto en el iuris consensus ni en la utilitatis communio, esto es, en el ámbito de lo estrictamente normativo, sino en la rerum dilectarum communio, es decir, en la comunión en torno de las cosas que se aman (Pegoraro, 2011, p. 227). El amor es la potencia fundamental de la vida en cuanto es fuente de concordia y unión, por esto es el principio originario y constitutivo del pueblo. Sobre ello, dice Agustín: "dos amores fundaron dos ciudades; la terrena, el amor propio hasta llegar a menospreciar a Dios, y la celestial, el amor a Dios, hasta llegar al desprecio de sí propio" (civ. Dei., 14, 28).

En conclusión, gracias al giro que Agustín da a la definición ciceroniana de república, solo la Ciudad de Dios puede denominarse como tal, pues únicamente ella cumple cabalmente con las exigencias que debe satisfacer una colectividad para considerarse república. La Ciudad de Dios es, en efecto, una sociedad religiosa basada en la fe en Cristo, abierta a todos los hombres a condición de que vivan en la fe. Ella nace y existe de un amor común por un bien común, conocido de idéntica manera gracias a la perfecta unidad de la fe. 


\section{Referencias}

\section{FUENTES PRIMARIAS}

Agustín de Hipona. (1951). Cartas. (Trad. L. Cilleruelo) Madrid: BAC.

Agustín de Hipona. (1957). Doctrina cristiana. (Trad. B. Martín). Madrid: BAC.

Agustín de Hipona. (1954). El bien del matrimonio. (Trad. L. Cilleruelo). Madrid: BAC.

Agustín de Hipona. (1988). La Ciudad de Dios. (Trad. V. Capánaga) Madrid: BAC.

Agustín de Hipona. (1948). Las costumbres de la Iglesia y las de los maniqueos. (Trad. V. Capánaga). Madrid: BAC.

Agustín de Hipona. (1985). La Trinidad. (Trad. L. Arias). Madrid: BAC.

Cicerón, M.T. (1991). Sobre la república. (Trad. Á. D’Ors). Madrid: Editorial Gredos.

Cicerón, M.T. (1994). Sobre los deberes. (Trad. J. Guillén) Barcelona: Ediciones Altaya.

\section{BIBLIOGRAFÍA SECUNDARIA}

Borón, A. (2000). La filosofía politica clásica: de la Antigüedad al Renacimiento. Buenos Aires: Consejo Latinoamericano de Ciencias Sociales.

Brown, P. (2003). Agustin de Hipona. (Trad. S. Tovar \& R. Tovar). Madrid: Acento Editorial.

Escobar, L. (1973). Régimen de familia en el derecho romano. Cali: Universidad de San Buenaventura.

Flórez, A. (2004). San Agustín. La persuasión de Dios. Bogotá: Panamericana Editorial.

Gilson, E. (1954). Las metamorfosis de la Ciudad de Dios. (Trad. B. Agüero). Buenos Aires: Editorial Troquel S. R. L.

Harrison, C. (2000). Augustine. Christian Truth and Fractured Humanity. New York: Oxford University Press. 
Markus R. (1970). Saeculum: History and Society in the Theology of St. Augustine. New York: Cambridge University Press.

Mas, S. (2006). Pensamiento Romano. Una historia de la filosofia en Roma. Valencia: Tirant lo Blanch.

O’Daly, G. (2004). Augustine's City of God. A Reader's Guide. New York: Oxford University Press.

Pegoraro, J. (2011). San Agustín y el concepto ciceroniano de república. Etiam, 6, pp. 223-230. 